\title{
Participatory design of a preliminary safety checklist for general practice
}

\begin{tabular}{|c|}
\hline Abstract \\
\hline $\begin{array}{l}\text { Background } \\
\text { The use of checklists to minimise errors is well } \\
\text { established in high reliability, safety-critical } \\
\text { industries. In health care there is growing interest } \\
\text { in checklists to standardise checking processes } \\
\text { and ensure task completion, and so provide } \\
\text { further systemic defences against error and } \\
\text { patient harm. However, in UK general practice } \\
\text { there is limited experience of safety checklist use. }\end{array}$ \\
\hline $\begin{array}{l}\text { Aim } \\
\text { To identify workplace hazards that impact on } \\
\text { safety, health and wellbeing, and performance, } \\
\text { and codesign a standardised checklist process. }\end{array}$ \\
\hline $\begin{array}{l}\text { Design and setting } \\
\text { Application of mixed methods to identify system } \\
\text { hazards in Scottish general practices and } \\
\text { develop a safety checklist based on human } \\
\text { factors design principles. }\end{array}$ \\
\hline $\begin{array}{l}\text { Method } \\
\text { A multiprofessional 'expert' group ( } n=7) \text { and } \\
\text { experienced front-line GPs, nurses, and practice } \\
\text { managers ( } n=18 \text { ) identified system hazards } \\
\text { and developed and validated a preliminary } \\
\text { checklist using a combination of literature review, } \\
\text { documentation review, consensus building } \\
\text { workshops using a mini-Delphi process, and } \\
\text { completion of content validity index exercise. }\end{array}$ \\
\hline $\begin{array}{l}\text { Results } \\
\text { A prototype safety checklist was developed } \\
\text { and validated consisting of six safety domains } \\
\text { (for example, medicines management), } 22 \\
\text { sub-categories (for example, emergency drug } \\
\text { supplies) and } 78 \text { related items (for example, } \\
\text { stock balancing, secure drug storage, and cold } \\
\text { chain temperature recording). }\end{array}$ \\
\hline $\begin{array}{l}\text { Conclusion } \\
\text { Hazards in the general practice work system } \\
\text { were prioritised that can potentially impact on } \\
\text { the safety, health and wellbeing of patients, GP } \\
\text { team members, and practice performance, } \\
\text { and a necessary safety checklist prototype } \\
\text { was designed. However, checklist efficacy in } \\
\text { improving safety processes and outcomes is } \\
\text { dependent on user commitment, and support } \\
\text { from leaders and promotional champions. } \\
\text { Although further usability development and } \\
\text { testing is necessary, the concept should be of } \\
\text { interest in the UK and internationally. }\end{array}$ \\
\hline $\begin{array}{l}\text { Keywords } \\
\text { checklists; general practice; human factors; } \\
\text { participatory design, patient safety. }\end{array}$ \\
\hline
\end{tabular}

\section{INTRODUCTION}

A recent evidence scan estimated that $1-2 \%$ of patient consultations with primary care clinicians may involve adverse events. ${ }^{1}$ This is potentially significant given that there are around 1 million consultations daily in the UK. ${ }^{2}$ However, it is well established that the nature, scale, and organisation of patient care in general medical practice are characterised by an inherent complexity and uncertainty, making the reliable delivery of safe and effective clinical management particularly problematic. ${ }^{3}$

Additionally the design quality of systems, technology, and related checking processes to support patient safety in general practice can be variable, unsafe, and ineffective. ${ }^{1,4-13}$ Clinicians and staff often struggle to cope with daily workloads while also attempting to manage a range of other human factors interaction issues (Box 1) that may further compromise performance and safety, for example: sub-optimal work system designs (such as usability of IT systems); organisational constraints (such as responding to contractual incentives and increasing patient demand); limited resource availability (such as real-term decreases in allocated funding); and

P Bowie, PhD, programme director, Department of Postgraduate GP Education, NHS Education for Scotland, Glasgow, and honorary senior lecturer, Department of General Practice and Primary Care, Institute of Health and Wellbeing, University of Glasgow, Glasgow. J Ferguson, DHealth Psy, research and education coordinator; M MacLeod, MBA, national practice management learning and development coordinator; S Kennedy, RGN, MSc, national learning and development coordinator for GP nursing; D McNab, MRCGP, GP and associate adviser; M Kelly, PhD, FRCGP, director of postgraduate GP education; J McKay, BSc(Hons), MD, FRCGP, GP and assistant director,

Department of Postgraduate GP Education, NHS Education for Scotland, Glasgow. C de Wet, MMed(Fam), FRCGP, GP and associate adviser, Department of Postgraduate GP Education, NHS Education for Scotland, Glasgow, and PhD external political pressures (such as meeting targets for patient access).

In this type of high-intensity and complex working environment it is inevitable, therefore, that 'human error' will occur and that patients are sometimes, avoidably, harmed as a result. ${ }^{14-15}$ Safety incidents may have clear and obvious physical and psychological effects on the health, wellbeing, and trust of patients and relatives. But they can also impact negatively on the physical health Ifor example, sharps injury or infection) and emotional wellbeing of clinicians and staff lfor example, stress and anxiety related to the second victim syndrome'), while also affecting individual and team performance. ${ }^{16,4-6}$

As part of the evolving patient safety agenda ${ }^{1}$ there is growing interest in human factors-based interventions such as 'checklists' to standardise necessary checking processes and act as cognitive aids to ensure task completion by care teams. ${ }^{17}$ The expectation is that this will support workforce safety performance and provide further systemic defences against error and preventable harm to patients. ${ }^{18-19}$

The limited evidence in general practice suggests that inconsistent and unreliable candidate, Department of General Practice and Primary Care, Institute of Health and Wellbeing, University of Glasgow, Glasgow. S Atkinson, PhD, senior research fellow, Human Factors Research Group, University of Nottingham, Nottingham.

\section{Address for correspondence}

Paul Bowie, Medical Directorate, NHS Education for Scotland, 2 Central Quay, Glasgow G3 8BW. UK.

E-mail: paul.bowieanes.scot.nhs.uk

Submitted: 25 Nov 2014; Editor's response: 4 Jan 2015; final acceptance: 25 Feb 2015.

\section{(cBritish Journal of General Practice}

This is the full-length article (published online 27 Apr 2015) of an abridged version published in print. Cite this article as: $\mathbf{B r} \mathbf{J}$ Gen Pract 2015; DOI: 10.3399/bjgp15X684865 


\section{How this fits in \\ Checklists are commonly used in high reliability industries and in many secondary care settings to improve safety systems and processes. The lack of standardised, timely, and consistent checking processes are known to be contributory factors in significant events. However, there is limited experience of taking a systems- based approach to checking safety issues of importance and improving related reliability in general practice. This study identified safety hazards across the general practice work system, and codesigned a prototype checklist based on published evidence, practitioner experience, and human factors principles. A safety checklist provides a method to engage front-line staff in the timely and consistent checking of important issues that can impact on the safety, health, and wellbeing of people and practice performance. The preliminary checklist has potential as an intervention to measure, monitor, and improve elements of general practice safety and performance.}

checking processes can compromise care quality and safety, and are cited as contributory factors in significant events. ${ }^{1,4-13}$ Examples include the unsafe management of controlled drugs (such as correlation of recorded and actual stock levels is lacking), emergency equipment maintenance Isuch as the practice oxygen supply is at insufficient levels) and medication storage lsuch as drugs are stored at incorrect temperatures or are outwith expiry dates).

This study focused on integrating and improving the design and timely adherence to checking processes of direct relevance to the safety and wellbeing of patients and visitors, the GP team, and overall practice performance. Adopting a consistent, methodical, and measurable approach to checking processes may lead to the standardisation and high reliability of task performance and the safety systems concerned across the working environment. ${ }^{20-21}$ The aims, therefore, were to:

- identify and prioritise workplace hazards that are known to impact on the safety, health, and wellbeing of patients, visitors, and GP team members, and organisational performance using a human factors work system model; ${ }^{22-23}$ and

- codesign and validate a standardised, integrated checklist process for general practices which reflects system-wide safety hazards and risks.

\section{METHOD}

\section{Study design}

A mixed methods study was undertaken which included literature and practice policy document reviews; formation of an 'expert' steering group; consensus generating workshop meetings with GPs, practice managers and nurses; and a content validity index exercise. ${ }^{24}$

\section{Conceptual influences}

A participatory design approach ${ }^{25-26}$ to identifying hazards and codeveloping the safety checklist was adopted. This is a user-centred method that seeks to actively involve front-line groups with the greatest subject matter expertise in a codesign process. In this way they can inform design issues so the outcome meets their needs and usability concerns are addressed iteratively prior to implementation.

The identification of safety hazards was informed by the Systems Engineering Initiative for Patient Safety (SEIPS) work system model.22-23 The SEIPS model seeks to explain work system designs from a human factors and patient safety perspective by adopting a 'whole system' approach that focuses on the interactions and interdependencies of five related components (people, tasks, tools and technologies, physical environment, and organisational conditions), and how these impact on 'outcomes' such as safety, performance and health and wellbeing. To illustrate the systems-centred SEIPS approach a summary of a checkingprocess related significant event analysis is outlined in Box 1.

\section{Recruitment of study participants}

Convenience samples of study participants were recruited by email from three professional networking groups (with an interest in patient safetyl based in NHS Scotland during May 2014. Groups 1 and 2 were the national networking and learning groups for GP managers and nurses respectively, with both comprising 15 members and each member representing a territorial NHS board region. The third group was the west of Scotland GP Audit Development Group ( $n=14)$, a well established group involved in educationally assessing quality improvement activities undertaken by GPs.

\section{Review of checking process-related practice documentation}

Those indicating an interest in study participation were requested to voluntarily send (in confidence), examples of safety- 
related policies, protocols, and procedures (Appendix 1) to help inform the study purpose, scope, and potential checklist development. The documentation was jointly reviewed by two authors to identify safety-critical checking processes of interest.

\section{Initial draft of checklist content}

A core 'expert' steering group was formed to oversee the hazard identification and checklist design, and validation. The group included three GPs with educational roles related to patient safety, a national practice manager education lead, a national general practice nurse education lead, a patient safety scientist, and a health psychologist with safety research experience. The initial draft checklist content lof nine main themes, 32 subcategories and 40 related safetycritical issues) was developed iteratively by the group from a combination of issues raised in the literature, checking processes identified from the aforementioned policy

\section{Box 1. Example of a patient safety incident related to checking processes and relevant sociotechnical interactions informed by the SEIPS model}

\begin{tabular}{|c|c|c|c|c|c|c|c|}
\hline \multicolumn{8}{|c|}{$\begin{array}{l}\text { Brief safety incident description: a tall, overweight 55-year-old male patient collapsed in the waiting room at } 4.45 \mathrm{pm} \text { while attending the surgery with a family } \\
\text { member. The practice team responded to the incident as per the emergency protocol. However, the CPR defibrillator battery was not usable because it was not } \\
\text { charged and the adrenaline was out-of-date. A lack of timely checking processes was found to be a major contributory factor. The patient survived but a formal } \\
\text { complaint was received by the practice }\end{array}$} \\
\hline \multirow[b]{2}{*}{$\begin{array}{l}\text { People } \\
\text { (Patient, clinician, } \\
\text { manager, } \\
\text { administrator; } \\
\text { team; physical, } \\
\text { cognitive, and } \\
\text { psychosocial } \\
\text { characteristics) }\end{array}$} & \multirow[b]{2}{*}{$\begin{array}{l}\text { Task(s) } \\
\text { (Variety, content, } \\
\text { complexity, } \\
\text { physical and } \\
\text { psychological } \\
\text { demands) }\end{array}$} & \multirow[b]{2}{*}{$\begin{array}{l}\text { Tools and } \\
\text { Technology } \\
\text { (Medical devices, } \\
\text { drugs, information } \\
\text { technology, } \\
\text { other tools and } \\
\text { technologies) }\end{array}$} & \multirow[b]{2}{*}{$\begin{array}{l}\text { Physical } \\
\text { environment } \\
\text { (Physical layout; } \\
\text { workstation } \\
\text { design; noise, } \\
\text { lighting, } \\
\text { temperature) }\end{array}$} & \multirow[b]{2}{*}{$\begin{array}{l}\text { Organisation } \\
\text { (Formal and } \\
\text { informal } \\
\text { organisation; } \\
\text { safety climate; } \\
\text { policies, protocols, } \\
\text { and procedures; } \\
\text { organisation } \\
\text { structure and } \\
\text { management) }\end{array}$} & \multirow[b]{2}{*}{$\begin{array}{l}\text { External } \\
\text { environment } \\
\text { (Contractual, } \\
\text { accreditation } \\
\text { and regulatory } \\
\text { demands; political } \\
\text { and health } \\
\text { authority decision } \\
\text { makingl }\end{array}$} & \multicolumn{2}{|c|}{ OUTCOMES } \\
\hline & & & & & & $\begin{array}{l}\text { People } \\
\text { ISafety, } \\
\text { performance, } \\
\text { health and } \\
\text { wellbeing, } \\
\text { care, and job } \\
\text { satisfaction }\end{array}$ & $\begin{array}{l}\text { Organisation } \\
\text { (Performance, } \\
\text { productivity, } \\
\text { and business } \\
\text { reputation }\end{array}$ \\
\hline $\begin{array}{l}\text { - Physically } \\
\text { large adult male } \\
\text { patient collapsed } \\
\text { in surgery waiting } \\
\text { room area } \\
\text { - Very emotional } \\
\text { and anxious } \\
\text { family member in } \\
\text { attendance } \\
\text { - Clinicians } \\
\text { with relevant } \\
\text { experience, } \\
\text { training, and } \\
\text { knowledge } \\
\text { - Administrators } \\
\text { trained in } \\
\text { emergency } \\
\text { response } \\
\text { - Clinicians } \\
\text { fatigued after long } \\
\text { day and without a } \\
\text { break or lunch } \\
\text { - Waiting room } \\
\text { full of attending } \\
\text { patients }\end{array}$ & $\begin{array}{l}\text { - Emergency } \\
\text { alarm activated by } \\
\text { receptionist } \\
\text { - Relevant } \\
\text { team members } \\
\text { responded rapidly } \\
\text { - Administrator } \\
\text { phoned emergency } \\
\text { ambulance } \\
\text { - GP retrieved } \\
\text { emergency } \\
\text { equipment } \\
\text { - Infrequent, } \\
\text { complicated, } \\
\text { stressful, and } \\
\text { physically } \\
\text { demanding task } \\
\text { - Practice nurse } \\
\text { cared for family } \\
\text { member } \\
\text { - Administrators } \\
\text { moved older, sick } \\
\text { patients to linked } \\
\text { corridor }\end{array}$ & $\begin{array}{c}\text { - Functioning } \\
\text { emergency alarm } \\
\text { system and speed } \\
\text { dial to ambulance } \\
\text { service } \\
\text { - Defibrillator } \\
\text { unusable because } \\
\text { ageing battery did } \\
\text { not charge } \\
\text { - Usability issues } \\
\text { with defibrillator } \\
\text { caused minor } \\
\text { confusion } \\
\text { - Design of blood } \\
\text { pressure monitor } \\
\text { is limited for } \\
\text { emergencies } \\
\text { • Stock of } \\
\text { adrenaline available } \\
\text { but out-of-date }\end{array}$ & $\begin{array}{l}\text { - Small waiting } \\
\text { room area made it } \\
\text { difficult for team to } \\
\text { interact effectively } \\
\text { with patient and } \\
\text { equipment } \\
\text { - Layout/design } \\
\text { contributed to a } \\
\text { lack of privacy and } \\
\text { dignity } \\
\text { - Noise from other } \\
\text { waiting patients are } \\
\text { a distraction }\end{array}$ & $\begin{array}{l}\text { - Good levels of } \\
\text { team working and } \\
\text { communication } \\
\text { demonstrated } \\
\text { - CPR retraining for } \\
\text { two attending team } \\
\text { members was } \\
\text { overdue } \\
\text { - Ad hoc and } \\
\text { informal checking } \\
\text { process for } \\
\text { emergency } \\
\text { equipment } \\
\text { maintenance and } \\
\text { relevant drugs, and } \\
\text { CPR training } \\
\text { - Prevailing safety } \\
\text { climate did not } \\
\text { prioritise related } \\
\text { checking processes } \\
\text { - Previous checking } \\
\text { process significant } \\
\text { events, but limited } \\
\text { collective learning } \\
\text { by practice team } \\
\text { - Organisational } \\
\text { clarity required } \\
\text { regarding checking } \\
\text { of safety-related } \\
\text { processes and } \\
\text { issues }\end{array}$ & $\begin{array}{l}\text { - Main practice } \\
\text { quality and } \\
\text { safety focus } \\
\text { was on meeting } \\
\text { contractual } \\
\text { demands and } \\
\text { maximising access } \\
\text { to meet increasing } \\
\text { patient demand } \\
\text { - Real-term } \\
\text { decreases in } \\
\text { practice income led } \\
\text { to delayed decision } \\
\text { on replacement } \\
\text { defibrillator } \\
\text { equipment } \\
\text { - Heavy workload } \\
\text { demands impacted } \\
\text { on delayed CPR } \\
\text { training attendance } \\
\text { and available } \\
\text { time for routine } \\
\text { emergency } \\
\text { equipment and/ } \\
\text { or drugs checking } \\
\text { processes }\end{array}$ & $\begin{array}{l}\text { Team members } \\
\text { Feelings of } \\
\text { guilt and } \\
\text { embarrassment; } \\
\text { apportioning } \\
\text { individual blame; } \\
\text { worsening } \\
\text { interpersonal } \\
\text { relationships; } \\
\text { added work stress } \\
\text { and anxiety; } \\
\text { individual on } \\
\text { related sick leave }\end{array}$ & $\begin{array}{l}\text { Practice } \\
\text { Formal complaint } \\
\text { received from } \\
\text { patient's family; } \\
\text { adverse media } \\
\text { publicity and in } \\
\text { local community; } \\
\text { deterioration in } \\
\text { practice family } \\
\text { relations }\end{array}$ \\
\hline
\end{tabular}


documentation review and professional experience in the workplace.

\section{Consensus building workshops}

Consensus building in face-to-face workshop meetings and the use of followup email and telephone discussions was informed by adapting the Delphi technique - an iterative method for structuring a communication process involving expert or informed groups to achieve a particular goal - which when used in face-to-face meetings is known as a mini-Delphi. ${ }^{27}$ The identification and potential impact of safety hazards, generation, and refinement of the checklist content on an iterative basis lincluding suggested frequency of checklist use and how items should be checked) was achieved by in-depth critical discussion, debate, and consensus agreement during two 4-hour workshops with study participants. During this process, the early draft checklist version and examples of related hazards were used as prompts to facilitate open discussions and small group work 'reflect and feedback' sessions. The workshop moderator took contemporaneous field notes throughout and retained all flip chart data generated by participants for subsequent analysis. After each meeting, the steering group members jointly reviewed and agreed checklist content by merging, amending, reducing, editing and, where necessary, deleting main themes, subcategories, and related issues to further enhance relevance and clarity of all items based on the feedback and consensus of the intended users. Postworkshop discussions and clarifications also took place via email and telephone between the moderator and all participants. From this a preliminary safety checklist consisting of six main safety-critical themes, 22 subcategories and 78 related items were generated.

\section{Content Validity Index (CVI) exercise}

A CVI exercise to quantify the strength of agreement on all aspects of the checklist content and further enhance relevance and clarity was undertaken by the 18 workshop participants. The relevance and clarity of each retained checklist theme, subcategory, and related item were assessed by asking participants to rate them using a validated 4-point ordinal scale: $1=$ not relevant, 2 = somewhat relevant, 3 = quite relevant and 4 =very relevant). A minimum $80 \%$ agreement (15 out of 18) was required to endorse each theme, subcategory, and item for checklist inclusion by assigning a rating of at least 3 out of 4 , to establish content validity beyond the 0.05 level of significance. ${ }^{28}$ Participants were also asked to suggest other possible issues for checklist inclusion. Due to space limitations only the CVI rating scores for the core checklist themes and subcategories are reported.

\section{Preliminary checklist design and usability principles}

Checklist design and usability is made more effective and may improve human perception and interaction by paying close attention to the legibility, organisation, and comprehension of information displayed. ${ }^{28-29}$ Basic usability guiding principles, ${ }^{29-31}$ were followed to enhance checklist design Ifor example, a long checklist should be 'catalogued' in multiple pages; content should be validated with intended users; and a landscape layout style should be used with room for comments and/or actions and/or review date).

\section{RESULTS}

Personal, professional, and practice characteristics of study participants

Eighteen general practice clinicians and managers participated in the study, which equates to an overall response rate of $41 \%$ (18 out of 44). Of the professional groups approached, 10 practice managers $(66 \%)$, five practice nurses $(33 \%)$ and three GPs agreed to participate (21\%). The majority were female $(n=13,72.2 \%)$, in the age groups $45-54$ and $\geq 55$ years, and based in training practices ( $n=13,72.2 \%$ ). Their professional details and practice characteristics are outlined in Table 1.

\section{Safety hazards identified across the general practice work system}

A range of hazards was identified and themed as six different safety domains (for example, medication management and information systems) by participants, which reflected the breadth of the general practice work system and informed checklist development. Identified hazards were known threats to the health and wellbeing of patients (for example, lack of available adrenaline in an emergency situation), practice visitors (for example, accidental injury from loose carpets or tiles) and GP team members (for example, infection as a result of cross-contamination from bodily fluids). Similarly, hazards were also identified that could impact on the safe performance and productivity of GP team members and the practice organisation (for example, malfunctioning emergency medical equipment and an outof-date business continuity plan). Selected 


\section{Box 2. Selected examples of identified potential hazards in the general practice environment using the SEIPS work system model to inform checklist content development}

\begin{tabular}{|c|c|}
\hline $\begin{array}{l}\text { Safety domains }(n=6) \\
\text { and subcategories }(n=22)\end{array}$ & $\begin{array}{l}\text { Potential hazards: patient, GP team members and practice } \\
\text { organisational outcomes (for example, quality, safety, health, } \\
\text { wellbeing, performance) }\end{array}$ \\
\hline $\begin{array}{l}\text { Medication management } \\
\text { (controlled drugs; emergency drugs } \\
\text { and equipment; prescriptions and pads; } \\
\text { vaccinations; all other drugs) }\end{array}$ & $\begin{array}{l}\text { - Lack of in-date stock may lead to inability to treat acutely ill } \\
\text { patient } \\
\text { - Lack of necessary emergency drugs, or out-of-date emergency } \\
\text { drugs can lead to patient safety being compromised, for } \\
\text { example, adrenaline for anaphylaxis } \\
\text { - Protects these prescription-related items from potential theft } \\
\text { which can lead to unauthorised prescriptions of high risk drugs } \\
\text { being dispensed to vulnerable patients or members of the public } \\
\text { who may harm themselves as a result } \\
\text { - Safe and secure keeping is necessary to prevent theft and } \\
\text { misuse which could harm patients and members of the public } \\
\text { - Lack of in-date stock may lead to inability to provide timely } \\
\text { disease prevention treatments to patients } \\
\text { - Patients, including children, ingesting non-prescribed } \\
\text { medications and suffering related harms }\end{array}$ \\
\hline $\begin{array}{l}\text { Housekeeping } \\
\text { (infection control; stocking of clinical } \\
\text { rooms; confidential waste; clinical } \\
\text { equipment maintenance) }\end{array}$ & $\begin{array}{l}\text { - Staff and patients, including children, obtaining a needle stick } \\
\text { injury from overfilled 'sharps' bins } \\
\text { - Patients at risk of infection from spilled hazardous waste on } \\
\text { clinical surfaces and/or equipment } \\
\text { - Patients and staff at risk of cross-contamination from blood } \\
\text { and/or bodily fluids } \\
\text { - Risk of cross-infections from, for example, people, equipment, } \\
\text { and clinical surface areas } \\
\text { - Breaches of patient confidentiality can impact on patient safety } \\
\text { via patients' suffering psychological harm from knowing their } \\
\text { medical history has been disclosed publicly } \\
\text { - Malfunctioning equipment (for example defibrillator or blood } \\
\text { pressure monitoring equipment) can impact on the safety of } \\
\text { patient care by providing un-calibrated readings that may result } \\
\text { in false reassurance of clinical condition and erroneously affect } \\
\text { decision making }\end{array}$ \\
\hline $\begin{array}{l}\text { Information systems } \\
\text { (business continuity plan is up-to-date; } \\
\text { verifiable back-up of all IT systems; data } \\
\text { protection; record keeping) }\end{array}$ & $\begin{array}{l}\text { - Can impact on how safe patient care is delivered in an } \\
\text { emergency situation; for example electrical outage to the } \\
\text { practice affecting IT systems and how to manage and deliver } \\
\text { care in such a situation }\end{array}$ \\
\hline $\begin{array}{l}\text { Practice team } \\
\text { (registration checks; CPR and } \\
\text { anaphylaxis training; induction } \\
\text { processes; access to patient safety- } \\
\text { related training) }\end{array}$ & $\begin{array}{l}\text { - Ensure all clinicians are registered with professional regulators. } \\
\text { Patient safety-critical checks that protect the local patient } \\
\text { population and the practice as an organisation }\end{array}$ \\
\hline $\begin{array}{l}\text { Patient access and identification } \\
\text { (access information for patients; } \\
\text { standardised patient ID verification) }\end{array}$ & $\begin{array}{l}\text { Numerous significant events in general practice are related } \\
\text { to mix-ups over patient identification leading to patient's being } \\
\text { subjected to unnecessary treatments, hospital visits, and } \\
\text { investigations, and breaches of confidentiality which can cause } \\
\text { avoidable physical and emotional harm }\end{array}$ \\
\hline $\begin{array}{l}\text { Health and safety } \\
\text { (building safety and insurance; } \\
\text { environmental awareness; staff health } \\
\text { and wellbeing) }\end{array}$ & $\begin{array}{l}\text { - Although a medical establishment, a first aid arrangement is } \\
\text { still a safety requirement similar to any other place of work } \\
\text { - Hazards in the workplace which are not identified and attended } \\
\text { to can lead to harm (for example, a patient sustaining a head } \\
\text { injury from walking into a low lying light) } \\
\text { - Staff can be subject to abuse, anger, threatening behaviour, and } \\
\text { violence and should be trained to manage these situations to } \\
\text { protect the safety and wellbeing of themselves and patients. }\end{array}$ \\
\hline
\end{tabular}

examples of these hazards are described in detail in Box 2 (see Appendix 2 for a detailed listing).
Safety checklist development, validation, and frequency of use

A preliminary safety checklist was developed and validated (Appendix 3) which consists of six domains (for example, medicines management), 22 subcategories (for example, controlled drugs) and 78 related items (for example, monthly stock reconciliation undertaken). The contents were judged by participants to be safety issues of priority across the general practice work system that required routine checks to minimise the risks of hazards to people and organisational practice performance.

Participants unanimously agreed that the checklist should be consistently applied at least three times per calendar year (that is once every 4 months) in order to ensure necessary checking of identified safety issues within acceptable timescales. It was further agreed that commonsense judgements should be applied to those items that, for example, need to be checked annually or may not be applicable to all practices (for example, stocking of controlled drugs). The important issue is the implementation of a reliable, consistent but contextualised and flexible checking system. Methods for checking each safety issue were also suggested, such as documentation review, observations, and spot checks.

\section{Content validity index (CVI) exercise}

Checklist domains, subcategories, and related issues were endorsed by a minimum of 15 out of 18 participants who rated each item $\geq 3$ on the 4-point scale (Table 2). The overall CVI ratio for the preliminary checklist was 0.92. A range of suggestions from participants on enhancing the relevance, clarity, and usability of the checklist content was also captured and reviewed by the project steering group and incorporated, where judged appropriate.

\section{DISCUSSION}

\section{Summary}

The project aims were achieved in terms of identifying hazards across the wider work system that may threaten patient safety and those that can impact on the health, safety, and wellbeing of relatives, visitors, GP team members, and also practice organisational performance. A preliminary safety checklist process was then codesigned and validated by intended users as a means to serially monitor safety performance and potentially drive system improvements, where necessary. The checklist has a dual purpose in terms of acting as a traditional 'one-off' checklist aid 


\section{Table 2. Levels of agreement: number of raters' $(n=18)$ rating each checklist domain and sub-category $\geq 3$ (on a 4-point ordinal scale) and calculated content validity index (CVI) ratio}

\begin{tabular}{lcc} 
Safety checklist domain & Raters $\geq 3$ & $\mathbf{C V}^{\mathbf{a}}$ \\
\hline Medicines management & 18 & 1.0 \\
1. Controlled drugs & 18 & 1.0 \\
2. Emergency drugs and equipment & 18 & 0.94 \\
3. Prescriptions and pads & 18 & 0.94 \\
4. Vaccinations & 17 & 0.83 \\
5. All other drugs on premises & 18 & 0.83 \\
\hline Housekeeping & 18 & 0.83 \\
6. Infection control & 18 & 1.0 \\
7. Stocking of clinical rooms & 17 & 0.94 \\
8. Confidential waste & 18 & 0.94 \\
9. Clinical equipment maintenance & 17 & 0.94 \\
\hline Information systems & 18 & 0.94 \\
10. The practice business continuity plan is up-to-date? & 16 & 0.89 \\
11. The back-up of all significant IT systems can be verified? & 18 & 1.0 \\
12. Data protection & 18 & 0.94 \\
13. Record keeping & 18 & 0.94 \\
\hline Practice team & 18 & 0.89 \\
14. Registration checks & 18 & 1.0 \\
15. CPR and anaphylaxis training & 18 & 0.89 \\
16. Induction processes & 15 & 0.77 b \\
17. All staff have access to ongoing patient safety-related training opportunities & 18 & 0.94 \\
\hline Patient access and identification & 18 & 0.94 \\
18. Information for patients on how to access the practice urgently or in an & 18 & 0.94 \\
emergency is widely available in different formats & & \\
19. Standardised patient identification verification & 17 & 0.89 \\
\hline Health and safety & 18 & 0.89 \\
20. Building safety and insurance & 17 & 0.89 \\
21. Environmental awareness & 18 & 0.89 \\
22. Staff health and wellbeing & 18 & 0.89 \\
\hline
\end{tabular}

$\mathrm{CVI}=$ content validity index. ${ }^{\mathrm{a}} \mathrm{A} \mathrm{CVI}$ ratio of $\geq 0.8$ is necessary to minimise the possibilities of chance agreement on content validity and merit item inclusion in the checklist content. The proportion of expert raters in agreement (when there are six or more raters scoring 3 or 4 on the 4-point ordinal scale) establishes content validity beyond the 0.05 level of significance. The number of raters needed and the proportion that must be in agreement to establish item content validity is decided by application of the standard error of the proportion. ${ }^{b}$ Amended and moved to practice team domain. judgements of the users rather than to replace these. ${ }^{32}$

\section{Comparison with existing literature}

The six main checklist domains (for example, medicines management) are mostly addressed to some extent by existing high level quality indicators and standards developed for general practice in Australia, ${ }^{33}$ Canada, ${ }^{34}$ England, ${ }^{35}$ and New Zealand, ${ }^{36}$ although the latter all have a broader remit than 'safety'. On the overlapping issues, compared to the proposed checklist, these lack specific detail on the precise safety issues to be actually checked, the necessary frequency of checking and guidance on how to do this in order to minimise risks. Furthermore the checklist is intended to be implemented as part of a continuous improvement process to help monitor and enhance safety as part of routine practice rather than, for example, conducting checking processes just before an external inspection visit is due. From a safety perspective, the proposed checklist is arguably more comprehensive in scope, scale, and detail and may therefore assist practices to prepare for external inspection visits and measure improvement performance routinely.

\section{Strengths and limitations}

Checklists are not a panacea in fully resolving the issues that are identified as being amenable to checklist use. From a human factors perspective a checklist is an 'additional interface' between the user and the system, ${ }^{17}$ but users need to view it as having a high level of importance in overcoming recognised front-line problems and which enables them to apply "commonsense' judgements, ${ }^{32}$ otherwise it will be considered an irritation and remain unused. An externally imposed checklist process that lacks the flexibility, adaptability, and autonomy to contextualise it to suit local circumstances may struggle to be fully accepted and implemented effectively. 17,37 The related development process should also be dynamic and flexible and continuously incorporate feedback from users, experts, and the latest research evidence in order to enhance its front-line relevance, feasibility, and impact. ${ }^{38-42}$

Similarly, when implemented as a single intervention, checklists are often inadequate 'technical fixes' to what is in effect a sociocultural safety problem that is related, among other factors, to how seriously the issue of checking processes is taken within a team or organisation, particularly in complex working environments. ${ }^{32,42-43}$ Intended 
users may also resist or feel threatened by checklists because they are perceived to replace their expertise or decision making, or oversimplify the complexity of the working environment. ${ }^{37-44}$ Allied to user commitment and the support of healthcare leaders and promotional champions, checklist success is therefore more likely where structured step-by-step instructions for comparatively simple or straightforward technical tasks are necessary, variations in related performance already exists, and reliance on human memory is a known problem. ${ }^{17,32}$

A study limitation was the potential for bias as is evident through the pragmatic use of convenience samples of volunteer participants who over-represented specialty training practices, which are arguably more likely to be interested in learning and safety activities than nontraining practices. Only three GPs were recruited for workshops and participated in follow-up correspondence, although a further three GPs were represented on the study steering group. A larger study with purposive or representative samples of intended users would have minimised this type of bias. Although the codesign and validation approach taken was robust, more substantial usability testing with a wider range of users across the UK is necessary and greater evidence of the acceptability, feasibility, and safety impact of the checklist is clearly required.

\section{Implications for research and practice}

Additional usability testing is clearly necessary alongside a broader 'implementation package' that may include, for example, a short training intervention, educational guidance on managing sociocultural barriers to checklist use, development of a possible comparative audit and feedback system, and human factors advice on improving practice system designs.
Full-scale checklist implementation in UK general practices is not imminently likely and would also require some form of local or national incentivisation. At a fundamental level, however, the prototype checklist may be voluntarily used immediately by GP managers and nurses to update existing checking processes, or help inform the development of a new system of checks as another mechanism for proactively engaging with the nascent patient safety agenda. ${ }^{1}$ In this way, it can help provide reassurance by ensuring that some of the most safety-critical organisational tasks are actually carried out efficiently, on a timely basis and without ambiguity.

A further possibility is linking checklist implementation to the leadership, patient safety, and staff health and wellbeing responsibilities of practice managers via their annual appraisal and personal development plans, particularly as it brings together a range of safety-critical tasks that fall largely within their organisational job role and remit. Also, in light of the recent Francis report ${ }^{45}$ and Berwick review, ${ }^{46}$ there is potential to explore how this approach may contribute to Vincent et al's published framework for guiding healthcare organisations and care teams to measure and monitor safety and review progress against related objectives. ${ }^{47}$

The study adopted a robust, user-centred, and systems-based methodological approach to taking the first steps in the development of a necessary safety checklist prototype for the general practice work system. Usability testing is the necessary next stage before implementation issues in UK general practice can be considered more fully, while the concept should be of interest internationally. However, there are highly important sociocultural implementation issues that may need to be contained if future checklist use is to be effective and successful.

\section{Acknowledgements}

We offer sincere thanks to the following GP managers and nurses for their vital contributions to hazard identification and checklist development work: Barbara Watson, David Allen, Joanne Anderson, Fiona McKinlay, Mary Cuthbertson, Sheena Edwards, Ros O'Connor, Lindsey Falconer, Kevin Wood, Kate Mallin, Lauranne McMahon, Jennifer Wilson, Judith Thompson, Diane Elrick, Jan McCulloch, Jane McNiven, Claire Fernandez, Stacey Ross and Julie Crombie.

\section{Discuss this article}

Contribute and read comments about this article: bjgp.org/letters 


\section{REFERENCES}

1. Health Foundation. Evidence scan: levels of harm in primary care. http://uww. health.org.uk/publications/levels-of-harm-in-primary-care/ laccessed 19 Mar 2015).

2. Hippisley-Cox J, Vinoggradova Y. Trends in consultation rates in general practice 1995/1996 to 2008/2009: analysis of the QResearch database. London: QResearch and The Information Centre for Health and Social Care, 2009.

3. Barnett K, Mercer S, Norbury M, et al. The epidemiology of multimorbidity in a large cross-sectional dataset: implications for health care, research and medical education. Lancet 2012; 380: 37-43.

4. Sandars J, Esmail A. The frequency and nature of medical error in primary care: understanding the diversity across studies. Fam Pract 2003; 20(3): 231-236.

5. Dovey SM, Meyers DS, Phillips RL Jr, et al. A preliminary taxonomy of medical errors in family practice. Qual Saf Health Care 2002; 11(3): 233-238.

6. Elder NC, Dovey SM. Classification of medical errors and preventable adverse events in primary care: a synthesis of the literature. J Fam Pract 2002; 51(11): 927-932.

7. Bowie P, Halley L, McKay J. Laboratory test ordering and results management systems: a qualitative study of safety risks identified by administrators in general practice. BMJ Open 2014; 4(2): e004245.

8. Makeham MAB, Dovey SM, County M, et al. An international taxonomy for errors in general practice: a pilot study. Med J Aust. 2002;177(2): 68-72.

9. McKay J, Bradley N, Lough M, Bowie P. A review of significant events analysed in general medical practice: implications for the quality and safety of patient care. BMC Family Pract 2009; 10: 61.

10. Rosser W, Dovey S, Bordman R, et al. Medical errors in primary care: results of an international study of family practice. Can Fam Physician 2005; 51: 386-387.

11. Rubin G, George A, Chinn DJ, Richardson C. Errors in general practice: development of an error classification and pilot study of a method for detecting errors. Qual Saf Health Care 2003; 12: 443-447.

12. Avery AJ, Sheikh A, Hurwitz B, et al. Safer medicines management in primary care. Br J Gen Pract 2002; 52(Suppl): S17-22

13. Bowie P, McKay J, Kelly MH. Maximising harm reduction in early specialty training for general practice: validation of a safety checklist. BMC Family Pract 2012; 13: 62.

14. Feinmann J. Cutting out human error. BMJ 2008; 337: 1082-1083.

15. Reason J. Human error. 1st edn. Cambridge: Cambridge University Press, 1990.

16. Dekker S. Second victim: error, guilt, trauma and resilience. Boca Raton, FL: CRC Press, 2013

17. Degani A, Wiener E. Human factors of flight-deck checklists: the normal checklist. Moffett Field, CA: NASA, 1990.

18. Gawande A. The checklist: if something so simple can transform intensive care, what else can it do? New Yorker 2007; 10: 86-101.

19. Rosen MA, Pronovost PJ. Advancing the use of checklists for evaluating performance in health care. Acad Med 2014: 89(7): 963-965.

20. Reason, J. Combating omission errors through task analysis and good reminders. Qual Saf Health Care 2002: 11(1): 40-44.

21. Shillito J, Arfanis K, Smith A. Checking in healthcare safety: theoretical basis and practical application. Int J Health Care Qual Assur 2010; 23: 699-707.

22. Carayon P, Schoofs Hundt A, Karsh B-T, et al. Work safety design for patien safety: the SEIPS model. Qual Saf Health Care 2006; 15: i50-i58. DOI:10.1136/ qshc.2005.015842

23. Carayon P, Alvarado CJ, Hundt AS. Work system design in healthcare. In: Carayon P, ed. Handbook of human factors and ergonomics in healthcare and patient safety. Mahwah, NJ: Lawrence Erlbaum Associates, 2007: 61-78.

24. Yaghmaie F. Content validity and its estimation. J Med Educ 2003; 3(1): 23-25.

25. Hignett S, Wilson JR, Morris W. Finding ergonomic solutions - participatory approaches. Occup Med 2005; 55: 200-207.

26. Schuler D, Namioka A. Participatory design: principles and practices. Hillsdale, NJ: Erlbaum, 1993.

27. Lynn MR. Determination and quantification of content validity. Nurs Res 1986; 35(6): 382-385.

28. Hannifin S. Review of literature on the Delphi technique. http://umw.dcya.gov.ie/ documents/publications/Delphi_Technique_A_Literature_Review.pdf laccessed 23 Mar 2015).

29. Davies JM, Caird JK. Surgical safety checklist: a redesign using human factors guidelines background to the surgical safety checklist. Calgary, AL: University of Calgary, Canadian Patient Safety Institute, 2009.

30. Verdaasdonk EGG, Strassen PP, et al. Requirements for the design and implementation of checklists for surgical processes. Surgical Endoscopy 2009; 23: 715-726.

31. Scriven M. The logic and methodology of checklists. Western Michigan University, 2007. http://uww.wmich.edu/evalctr/archive checklists/papers/ logic\&methodology_dec07.pdf laccessed 23 Mar 2015).

32. Hales B, Terblanche M, Fowler R, et al. Development of medical checklists for improved quality of patient care. Int J Qual Health Care 2008; 20(1): 22-30.

33. Royal Australian College of General Practitioners National Expert Committee on Standards for General Practices. Standards for General Practices. 4th edition. South Melbourne: RACGP, 2010. http://www.racgp.org.au/your-practice/ standards/standards4thedition/preliminaries/preamble/ laccessed 7 Apr 2015).

34. Levitt C, Hilts L. Quality in family practice: book of tools. Hamilton, ON: McMaster Innovation Press, 2010

35. Care Quality Commission. Guidance about compliance: Essential standards about quality and safety. London: Care Quality Commission, March, 2010

36. The Royal New Zealand College of General Practice. Aiming for Excellence: RNZCGP Standard for General Practice (2011-2014). Wellington: RNZCGP, 2011.

37. Bosk CL, Dixon-Woods M, Goeschel CA, et al. The art of medicine: reality check for checklists. Lancet 2009; 374: 444-445.

38. Fourcade A, Blache J-L, Grenier C, et al. Barriers to staff adoption of a surgical safety checklist. BMJ Qual Saf2011; DOI:10.1136/bmjqs-2011-000094.

39. Hillgoss B, Moffat-Bruce $S$. The limits of checklists: handoff and narrative thinking. BMJ Qual Saf2013; DOI:10.1136/bmjgs-2013-002705

40. Ko HCH, Turner TJ, Finnigan M. Systematic review of safety checklists for use by medical care teams in acute hospital settings - limited evidence of effectiveness. BMC Health Serv Res 2011; 11: 211.

41. Kitto A, Grant R. Revisiting evidence-base checklists: interprofessionalism safety culture and collective competence. J Interprofessional Care 2014; DOI $10.3109 / 13561820.2014 .916089$

42. Tang R, Ranmuthgala G, Cunningham F. Surgical safety checklists: a review. ANZ J Surgery 2013; 84: 148-154.

43. Thomassen $\mathrm{O}$, Espeland A, Softeland $\mathrm{E}$, et al. Implementation of checklists in health care; learning from high reliability organisations. Scandinavian J Trauma, Resus and Emerg Med 2011; 19: 53.

44. Vats A, Vincent CA, Davies RW, et al. Practice challenges of introducing WHO surgical checklist: UK pilot experience. BMJ 2010; DOI: 10.1136/bmj.b5433.

45. Francis R. Independent Inquiry into care provided by Mid Staffordshire NHS Foundation Trust January 2005-March 2009. London: Department of Health, 2013

46. Berwick DM. A promise to learn - a commitment to act. Improving the safety of patients in England. London: Department of Health, 2013.

47. Vincent CA, Burnett S, Carthey C. The measurement and monitoring of safety. Drawing together academic evidence and practical experience to produce a framework for safety measurement and monitoring in healthcare. London: Health Foundation, 2013 
Appendix 1. Examples of written policies, protocols and procedures with an explicit safety focus submitted by participants to

inform study development

Controlled drugs policy

- Controlled drugs policy

- Hand hygiene policy

- Cleaning of premises policy

- Cleaning of equipment policy

- Cleaning materials policy

- General waste disposal policy

- Clinical waste disposal policy

- Sharps policy

- Needle stick injury policy

- Specimen handling protocol

- Business continuity plan

- Data protection registration

- New staff induction policy

- Locum doctor induction pack

- Staff equal opportunities policy

- Significant event policy

- Health \& safety policy

- Fire safety policy

- Electrical safety policy

- Disability access policy

- Public liability insurance

- Employer's liability insurance

- Laboratory test result handling protocol

- MMR vaccination protocol 


\section{Appendix 2. Example list of hazards in general medical practice identified by study participants for each checklist subcategory $(n=22)$ and how the safety, health and wellbeing of patients, GP team members, and practice organisation performance can be impacted}

1. Controlled drugs

2. Emergency drugs and equipment

3. Prescriptions and pads

4. Vaccinations

5. All other drugs on premises

6. Infection control

7. Stocking of clinical rooms

8. Confidential waste

9. Clinical equipment maintenance

10. The practice business continuity plan is up-to-date?

11. The back-up of all significant IT systems can be verified?

12. Data protection

\section{Record keeping}

14. Registration checks

15. CPR and anaphylaxis training

16. Induction processes

17. All staff have access to ongoing patient safety-related training opportunities (for example, needle stick injury, health and safety/fire safety, coding data)

18. Information for patients on how to access the practice urgently or in an emergency is widely available in different formats (for example, posters, leaflets, booklet, website)

19. Standardised patient identification (ID) verification
- Safe and secure keeping is necessary to prevent theft and misuse which could harm patients and members of the public

- Lack of in-date stock may lead to inability to treat acutely ill patient

- Lack of necessary emergency drugs or out-of-date emergency drugs can lead to patient safety being compromised, for example, adrenaline for anaphylaxis

- Similarly, malfunctioning emergency equipment, such as defibrillator with a 'dead' battery, may lead to an inability to resuscitate a collapsed patient

- Protects these items from potential theft which can lead to unauthorised prescriptions of high-risk drugs being dispensed to vulnerable patients or members of the public who may harm themselves as a result

- Poor re-ordering system may affect drug availability while lack of monitoring may lead to expiry of drug dates

- Safe and secure keeping is necessary to prevent theft and misuse which could harm patients and members of the public

- Lack of in-date stock may lead to inability to provide timely disease prevention treatments to patients

- Patients, including children, ingesting non-prescribed medications and suffering related harms

- Stolen drugs with the potential to cause harm without medical monitoring being used 'on the street'

- Efficacy and safety of medications being given if out-of-date

- Healthcare acquired infection is a major source of patient safety incidents across all health sectors.

- Staff and patients, including children, obtaining a needle stick injury from overfilled 'sharps' bins

- Patients at risk of infection from spilled hazardous waste on clinical surfaces/equipment

- Patients at risk of infection from non-immunised staff members

- Patients and staff at risk of cross-contamination from blood/bodily fluids

- Risk of cross-infections from, for example, people, equipment, and clinical surface areas

- Efficient stock management is a good system design issue to minimise time wasted locating these items

- Breaches of patient confidentiality can impact on patient safety via patients' suffering psychological harm from knowing their medical history has been disclosed publicly

- Malfunctioning equipment (for example, defibrillator or blood pressure monitoring equipment) can impact on the safety of patient care by providing un-calibrated readings which may result in false reassurance of clinical condition and erroneously affect decision making, for example inappropriate treatment with antihypertensive drugs due to poor condition of blood pressure monitor

- Can impact on how safe patient care is delivered in an emergency situation; for example, electrical outage to the practice affecting IT systems and how to manage and deliver care in such a situation

- Loss of, or limited access to, timely patient, medical, and prescribing data can lead to poorly informed clinical decision making

- Impacts on how evidence-based care is delivered potentially affecting the safety and efficacy of care provision because latest evidence and options are not available

- May lead to inappropriate access to patient records

- Poor data coding can lead to inappropriate/poor follow-up care

- Administration of drugs that cause avoidable side-effects (for example, allergic reactions)

- All are patient safety-critical checks which protect the local patient population and the practice as an organisation

- Although rare the practice teams should be trained to deal with these types of acute medical emergencies

- Staff or locum staff who are unfamiliar with safety-critical operations in the practice lfor example, the test results handling system, where emergency equipment is stored, how to gain access to GP in an emergency) may not follow correct procedures thereby potentially endangering patients

- Errors in coding can lead to poor or wrong medical care being provided as it is also shared with other health care sectors (for example, acute hospitals)

- Staff are aware of the risks of injury to themselves and patients and how to manage related accidents

- Patients not fully understanding how to access the practice for urgent or emergency care can further prolong illness, delays in treatment, and lead to unnecessary visits to other health services

- Numerous significant events in general practice are related to mix-ups over patient identification leading to patient's being subjected to unnecessary treatments, hospital visits, and investigations, and breaches of confidentiality which can cause avoidable physical and emotional harm 


\section{Appendix 2 continued. Example list of hazards in general medical practice identified by study participants for each checklist subcategory $(n=22)$ and how the safety, health and wellbeing of patients, GP team members, and practice organisation performance can be impacted}

20. Building safety and insurance

21. Environmental awareness

22. Staff health and wellbeing
- All are legally required and are there to protect the health, safety, and wellbeing of staff, patients, and visitors

- Notification of workplace accidents to the Health \& Safety Executive is required by law where an individual is required to take $\geq 3$ days off work as a consequence

- Although a medical establishment, a first aid arrangement is still a safety requirement similar to any other place of work

- Hazards in the workplace which are not identified and attended to can lead to harm; for example, a patient sustaining a head injury from walking into a low lying light

- Lack of thermal comfort can act as a distraction and make staff uncomfortable, thereby impacting on physical and mental health and increasing risk of error and poor performance

- Disorganisation of work and lack of clarity of roles and tasks can cause confusion, impact on mental health, and raise the risk of poor performance and error which could compromise patient safety

- Staff can be subject to abuse, anger, threatening behaviour, and violence and should be trained to manage these situations to protect the safety and wellbeing of themselves and patients

- Inadequate work station design, poor display screen and equipment training and practice, and lack of knowledge of manual handling guidance can impact on the physical (musculoskeletal injury) and mental health (for example, increased stress levels) and wellbeing of staff (for example, job satisfaction, and motivation), affecting performance levels and increasing the risks of errors being made (for example, attention levels when confirming patient ID on a computerised system or coding safety-critical patient data) 


\section{Appendix 3. Preliminary safety checklist for general practice [NHS Education for Scotland (draft version)]}

Why do we need such a checklist?

- Practice processes for checking priority safety issues that can impact on the health and wellbeing of patients and GP team members are highly variable and can be inconsistently applied which often contributes to why significant events happen.

- When combined with everyday complex workloads and stresses our memory spans and attention to detail are affected. This means we can often forget to undertake necessary checks of important safety tasks as planned - this can lead to errors being made, sometimes this has no real consequences but on other occasions it impacts negatively on patients, staff, and the practice.

- Checklists are used routinely in high risk industries such as aviation, nuclear power, and many hospitals to help staff remember critical tasks to be undertaken to ensure mistakes are not made and help make patients and the workplace safer

- The purpose of this checklist is to help ensure that tasks that are considered to be important from a safety perspective are actually checked on a routine basis and action is taken where needed to improve overall compliance. It aims to combine some existing checking processes into a single checking system which is undertaken every four months to ensure that the necessary checks are completed on a timely basis.

About the checklist

- The preliminary checklist was developed based on a combination of what we know can go wrong when things that should be checked routinely in practice are not, and the knowledge and expertise of a large group of practice managers, practice nurses, and GPs who contributed to its design and content over several workshops and surveys.

- It is important to note that it is not mandatory - but is a flexible guide, you will not necessarily agree with all of the content nor may it always be relevant to your practice. Use your own judgement and apply your own common sense. In these cases simply tick Yes for being fully compliant.

- As far as possible the development process was informed by human factors/systems thinking and guidance to make the checklist content relevant and understandable and to cover all aspects of the general practice workplace.

- If the checklist is not an improvement on existing checking processes then it is unlikely to be used, although bear in mind that some practices do this inconsistently and infrequently compared with others. The prevailing safety culture within a practice will also influence how seriously the checklist and checking processes are taken, that is: the checklist itself will not make the practice processes safer, like any improvement activity this is always down to the leadership, team-working and commitment of the GP team.

How to use the checklist

- Simply work your way through the checklist (it has been sub-divided to make it easier to follow and complete) and use a combination of checking and your own professional judgement to determine whether you are fully compliant with each of the issues outlined.

Fully

\section{Medication Management}

- Core safety issues to be checked

1. Controlled drugs

- Securely stored

- Up-to-date register exists

- Stock balances are undertaken at appropriate time intervals based on practice usage

- Any out-of-date stock is appropriately disposed

2. Emergency drugs \& equipment

- Your usual supplies are available in sufficient quantities

- Evidence of monthly stock check and expiry date rotation

- Evidence of monthly equipment check (for example, nebuliser, defibrillator, airways, anaphylaxis)

3. Prescriptions \& pads

- Securely stored

- Serial numbers are for prescription pads are recorded and stored

4. Vaccinations

- Cold chain temperature recording at least once daily

- Storage facility is locked and alarmed

- Your usual supplies are available in sufficient quantities

- Evidence of expiry date rotation

5. All other drugs on premises

- Storage facility is secure

- Your usual supplies are available in sufficient quantities

- Evidence of expiry date rotation

- Where a process exists for drugs to be returned to the practice, they are disposed of safely
Compliant? If No, please outline

Yes No Action Plan and Date Review

(•) (•) of Review

Date

\section{Document review}

and spot check

Document review

and spot check

Spot check

Document review and spot check

Document review and spot check 


\section{Appendix 3 continued. Preliminary safety checklist for general practice [NHS Education for Scotland (draft}

version)]

2. Housekeeping

- Core safety issues to be checked

6. Infection control

- All staff are trained in standard infection control precautions, including hand hygiene and sharps/bite/splash management

- Practice equipment is cleaned in line with practice policy

- Premises (floors, furnishings, surfaces, children's toys etc) are cleaned in line with practice policy

- Clinical waste is disposed of in line with practice policy

- Laboratory specimens are handled and stored in line with practice policy

- All staff are offered immunisation/boosters and are up-to-date lfor example, Hepatitis B, Rubella \& Influenzal

7. Stocking of clinical rooms

- Adequate personal protective equipment (PPE) is available

- Single use only sterile and non-sterile gloves in a range of sizes (where necessary) with latex-free alternatives are available

- Disposable hand and couch paper towels are available for use

- Liquid soap and Alco Gel are available

- Sharps containers are available, correctly assembled, out of reach of children, not filled beyond indicator mark and do not contain inappropriate waste

8. Confidential waste

- Identifiable patient information is disposed securely and confidentially (for example, shredded)

9. Clinical equipment maintenance

- There is a log of all significant items of clinical equipment

- There is a date system for when equipment should be serviced/working status checked

- All significant items of clinical equipment are calibrated or maintained in line with manufacturer's instructions/service recommendations

- Equipment which is not in use/maintained is disposed of appropriately

\section{Information systems}

- Core safety issues to be checked

10. The practice business continuity plan is up-to-date?

11. The back-up of all significant IT systems can be verified?

12. Data protection

- Latest software updates for all systems are installed (for example, formulary, EMIS, Vision)?

- Password security policy is being followed lincluding remote access protocols

13. Record keeping

- Clear evidence is available of accurate and up-to-date record keeping (for example, data coding and summarising, allergy updates)

\section{Fully}

Compliant? If No, please outline

Yes No Action Plan and

How to check?

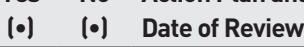

Review

Document review,

spot checks \&

discrete

observation

Spot checks

Spot checks and discrete observation

Document review, spot checks

\section{Fully}

Compliant? If No, please outline

Yes No Action Plan and

(•) (•) Date of Review

Review

How to check?

Document review

Spot check

Spot checks

Document

reviews and spot

checks

\section{Practice Team}

- Core safety issues to be checked

14. Registration checks

- All clinicians are registered with regulators

- All clinicians are registered with a Defence union

- Protecting Vulnerable Groups (PVG) checks are up-to-date

- Doctors are on the Performer's list

15. CPR and Anaphylaxis training

- All staff have up-to-date CPR training

- All clinical staff have up-to-date anaphylaxis training

16. Induction processes

- Induction process is up-to-date and any new staff are inducted appropriately for their role

- Up-to-date locum doctor/nurse induction pack is available and used

17. All staff have access to ongoing patient safety-related training opportunities (for example, needle-stick injury, health and safety/fire safety, coding datal

Fully

Compliant? If No, please outline

Yes No Action Plan and Review

(•) (•) Date of Review Date

reviews

Document

reviews

Document

reviews and spot

check

Document

reviews 


\section{Appendix 3 continued. Preliminary safety checklist for general practice [NHS Education for Scotland (draft}

version)]

\section{Patient access and identification}

- Core safety issues to be checked

18. Information for patients on how to access the practice urgently or in an emergency is widely available in different formats (for example, posters, leaflets, booklet, website)

19.Standardised patient identification (ID) verification

- The practice has a patient ID process using two approved patient identifiers and the practice team can describe how it is applied.

- Patient ID is always confirmed by all staff lover the telephone, face-to-face, when filing or handling records/results, writing prescriptions/referrals) using two of the following three characteristics: full name, date of birth and postal address (sex and $\mathrm{CHI}$ number if known/ available can also be used).

\section{Health \& Safety}

- Core safety issues to be checked

20. Building safety and insurance

- Practice policies on electrical and fire safety are adhered to

- Public and employer's liability insurance are up-to-date and displayed

- A system for recording and notifying accidents/violent incidents/near misses is in operation

- First aid arrangements are in place la first aid box is available and all staff are aware of trained first aiders)

21. Environmental awareness

- Routine checks for hazards to staff, patients, children and visitors are undertaken internally (for example, spillages, worn flooring, low hanging or protruding objects) and externally (for example, broken glass, spillages, obstructions)

- General thermal and lighting comfort (heating and cooling where necessary) is achieved within the premises

22. Staff health and wellbeing

- All partners and staff have clear work roles and designated tasks, and workloads are balanced

- The practice recognises the existence of work-related stress and accepts the need to identify its symptoms and resolve or manage contributory factors

- Regular team meetings are held to review practice performance, raise issues and problems and seek resolutions

- Access to training in handling threatening behaviour is available to all staff.

- The workstations of all display screen equipment users provide adequate space and are assessed to health and safety legal standards.

- All relevant staff are trained in manual handling procedures

\section{Fully}

Compliant? If No, please outline

Yes No Action Plan and Date Review

(•) (•) of Review

Date

Document review

and spot check

Document review

and discrete

observation
Fully

Compliant? If No, please outline

Yes No Action Plan and Date Review

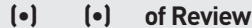

Date

Document re-

views

Spot checks

Document review

and spot check 